\title{
Effect of cooperative management on organizational agility with the mediating role of employee empowerment in public transportation sector
}

\author{
Efecto de la gestión cooperativa en la agilidad \\ organizacional con el papel mediador del \\ empoderamiento de los empleados en el sector del \\ transporte público
}

\author{
Bagher Asgarnezhad Nouri ${ }^{1}$ \\ Masume Mir Mousavi ${ }^{2}$ \\ University of Mohaghegh Ardabili (Iran) \\ University of Tehran (Iran)
}

Recibido el 19 de noviembre de 2017, aceptado el 10 de mayo de 2019

Publicado online el 8 de octubre de 2019

$\mathrm{N}^{\mathrm{o}}$ de clasificación JEL: M12

DOI: $10.5295 / \mathrm{cdg} .170873$ ba

\begin{abstract}
:
Different conditions in today's organizational societies have led many firms to identify effective strategies to achieve the goal of agility for rapid adaptation to ever-increasing environmental changes. Cooperative management and employee empowerment as emerging managerial concepts can play an important role in promoting agility in a variety of firms, including in the transportation sector. The main objective of the present study was to investigate the impact of cooperative management system on organizational agility by considering the mediating role of employee empowerment in public transportation. Statistical population of the research consisted of all employees of Tabriz and Suburbs Bus Company $(n=650)$. The estimated sample size based on Cochran's formula was 242 people. For measurement of variables, standard questionnaires were used. The research hypotheses were tested by using PLS and Spss and by modeling structural equations. Results suggested that cooperative management has a positive effect on both organizational agility and employee empowerment, and also empowerment has a significant effect on organizational agility. Further, it was concluded that employee empowerment mediates the relationship between cooperative management and organizational agility in Tabriz and Suburbs Bus Company. The present research is one of the few studies that has examined the relationship between the three concepts of organizational agility, cooperative management and employee empowerment in the transportation industry.
\end{abstract}

1 Department of Business Administration, Faculty of Literature and Humanities. Ardabil (Iran). asgarnezhad. research@uma.ac.ir

2 Department of Management and Accounting, Faculty of Pardis Farabi. Qom (Iran).m.moosavi_2013@alumni. ut.ac.ir 
Effect of cooperative management on organizational agility with the mediating role of employee empowerment in public transportation sector

\section{Keywords:}

Cooperative Management, organizational agility, employee empowerment, public transportation sector.

\section{Resumen:}

Las diferentes condiciones en las sociedades organizativas actuales han llevado a muchas empresas a identificar estrategias efectivas para lograr el objetivo de la agilidad para una rápida adaptación a los cambios ambientales cada vez mayores. La gestión cooperativa y el empoderamiento de los empleados como conceptos gerenciales emergentes pueden jugar un papel importante en la promoción de la agilidad en una variedad de empresas, incluso en el sector del transporte. El objetivo principal del presente estudio fue investigar el impacto del sistema de gestión cooperativa en la agilidad organizacional considerando el papel mediador del empoderamiento de los empleados en el transporte público. La población estadística de la investigación estuvo compuesta por todos los empleados de Tabriz y Suburbs Bus Company $(n=650)$. El tamaño de muestra estimado basado en la fórmula de Cochran fue de 242 personas. Para la medición de variables se utilizaron cuestionarios estándar. Las hipótesis de investigación se probaron utilizando PLS y Spss y modelando ecuaciones estructurales. Los resultados sugirieron que la administración cooperativa tiene un efecto positivo tanto en la agilidad organizacional como en el empoderamiento de los empleados, y también el empoderamiento tiene un efecto significativo en la agilidad organizacional. Además, se concluyó que el empoderamiento de los empleados media la relación entre la gestión cooperativa y la agilidad organizacional en Tabriz y Suburbs Bus Company. La presente investigación es uno de los pocos estudios que ha examinado la relación entre los tres conceptos de agilidad organizacional, gestión cooperativa y empoderamiento de los empleados en la industria del transporte.

\section{Palabras clave:}

Gestión cooperativa, agilidad organizacional, potenciación de los empleados, sector del transporte público. 


\section{INTRODUCTION}

Today, the overcrowding of cities and tendency to urbanization have increased the need of people in using transportation vehicles. As such, the existence of a secure, efficient, and economical public transportation system with the least destructive biological effects seems to be a necessary step in pursuit of sustainable development. As urban transportation is one of the main areas of economic development, it emphasizes the need for proper planning in urban transport (Nasrollahi \& Push Duzbashi 2017). Public transportation provides valuable benefits to our society. From the viewpoint of environmental protection, bus transportation helps reduce carbon dioxide emissions, reduces gasoline consumption and eliminates the potential traffic problems in urban areas (Qiu \& Li 2018). Although strategic management of urban public transportation has a history of about a century, some aspects of it are still unknown. There are many questions that both urban management theorists and professional planners have been trying to answer. This means that for the agility of organizational services, it is necessary to consider the agility requirement in employee empowerment. Moreover, given the involvement of employees and the use of employee experiences in matching the services and engaging employees in strategic decision-makings and organizational agility, the utmost effort should be made.

Cooperative management practices, regardless of the size of the company, are important to improve the financial success and implementation of the strategy. Cooperative engagement by all levels of the company is a useful way to increase the chances of success in the implementation of the strategy (Goodwin 2018). It can be said that cooperative management in general and employee participation in particular can well affect organizational decision-making in targeting, decision-making, problem-solving and creating changes in organizations. Many top executives and managers believe that in an environment where global competition and new technologies are its features, abandoning centralized control will increase the flexibility of the organization. In this regard, employee empowerment is the best decentralization philosophy. Empowerment is a valuable way of making balance between full management control and the freedom of employees (Zimmerman 1990).

In today's organizations, the focus on employee empowerment and the factors affecting it has increasingly grown. Additionally, there is evidence that employee empowerment has a positive impact on individuals' performance, their attitudes toward work and the performance of organizations (Tallon et al. 2018). On the other hand, in today's highly volatile environments, organizations need to operate their strategies and actions as quickly as possible. In this competitive environment, organizational agility has become an important merit of the company, which can have profound effects on the company's performance (Horabadi Farahani \& Salimi 2015). The term "agile" explains the speed and accountability of an organization in dealing with its internal and external events (Yaghoubi et al. 2011). In an agile organization that is faced with constant environmental changes, human resource capability plays an important role. Human resource empowerment can provide the necessary ground for the training of capable employees. As such, implementation of empowerment programs can help to improve organizational agility (Nikbakht et al. 2014). Employee empowerment makes organizations have a faster and easier respond in a competitive environment (Horabadi Farahani \& Salimi 2015). Nowadays, the environment of organizations, especially service organizations, is getting pregnant with many changes, opportunities and 
challenges the ability to deal with them can be expected from the organizations. On the one hand, having a strategic look at the changes and opportunities resulting from changes and, on the other hand, improving the organization's capabilities and infrastructure can be a good mechanism for the long-term and sustainable success of the organization. Given the importance of organizational agility as a tool to overcome the challenges of the third millennium, agility exploration, with an emphasis on cooperative management, can make a major leap in agility and high performance for public transportation companies. Agility is defined as the ability to boom and prosper in a constantly changing and unpredictable environment. Accordingly, organizations should not be afraid of changes in their working environments, nor avoid them; they rather should consider changes as opportunities in gaining competitive advantage in the marketplace (Maskell 2001).

A literature review of the research suggests that there are few studies examining the relationship between cooperative management variable and organizational agility. On the other hand, none of the previous studies have analyzed the mediating role of employee empowerment in this relationship. Therefore, with the aim of evaluating the role of cooperative management system on organizational agility through taking into account the mediating role of employee empowerment in the public transportation sector, this study will refer to the gap in the literature of the subject. The study, thus, is going to answer the question how much does the cooperative management system affect organizational agility with the mediating role of the employee empowerment? The structure of the article to the end includes the theoretical and empirical background of the research, the formulation of the hypotheses and methodology of the research, and finally, the findings of the research along with the conclusions and recommendations.

\section{LITERATURE REVIEW}

\subsection{Organizational Agility}

Organizations are now in the process of changes in environmental factors and should be compatible with it. Looking at the social trend in recent decades, it can be concluded that organizations must be compatible with changes that may take place in the future. The business environment today is dramatically changing; if an organization wants to be active and guarantee its survival, it must be compatible with future changes (Horabadi Farahani \& Salimi 2015). Organizational agility refers to the ability of flexibility to environmental changes by setting up products and delivering faster and more inclusive services to achieve sustainable competitive advantage (Baškarada \& Koronios 2018). In today's landscape of competitive business, organizational agility is critical to competitive success, because it reflects the ability of companies in understanding market changes (Lee et al. 2015). The concept of organizational agility has not been sufficiently considered in the management literature. Singh et al. (2013) argues that there is a need for better structuring. However, most studies of organizational agility have focused on the characteristics of agile organizations, not on basic organizational capabilities (Baškarada \& Koronios 2018). Singh et al. (2013) consider the origin of the concept of agility in management goes back to Harvard Marketing Review interview with Jack Welch, former chairman and CEO of GE, in which 
he emphasized the importance of "speed, agility, and simplicity" (Baškarada \& Koronios 2018). Agility can be viewed from different perspectives. For example, strategic agility refers to the ability to acquire new opportunities; Portfolio agility refers to the ability to transfer resources between business areas as quickly and efficiently as possible; and operational agility refers to the ability to exploit opportunities in an existing business model (Baškarada \& Koronios 2018). Different definitions of the researchers are presented in Table 1.

Table 1

Some definitions of organizational agility

\begin{tabular}{|c|c|}
\hline Author(s) & Conceptualization of agility \\
\hline Sharifi \& Zhang, 2001). & $\begin{array}{l}\text { Agility refers to the use of changes as inherent opportu- } \\
\text { nities in turbulent environment }\end{array}$ \\
\hline (Dove, 2002). & $\begin{array}{l}\text { Agility refers to the ability to survive and progress in the } \\
\text { variable and unpredictable environment }\end{array}$ \\
\hline (Erande \& Verma, 2008). & $\begin{array}{l}\text { Agility is the ability to respond to unpredictable changes } \\
\text { with quick response and profitability }\end{array}$ \\
\hline Janssen (2010) & $\begin{array}{l}\text { Agility is an organizational ability to react quickly and } \\
\text { effectively to an environment which can change radically }\end{array}$ \\
\hline Alzoubi et all (2011) & $\begin{array}{l}\text { Agility as a quick and preventative adaptation of } \\
\text { organizational elements to unexpected and unpredicted } \\
\text { changes. }\end{array}$ \\
\hline Cegarra-Navarro et al (2016) & $\begin{array}{l}\text { Organizational agility refers to the ability of the com- } \\
\text { pany to adapt to change. }\end{array}$ \\
\hline Teece et al (2016) & $\begin{array}{l}\text { Organizational agility is roughly synonymous with } \\
\text { flexibility. }\end{array}$ \\
\hline Baškarada \& Koronios (2018) & $\begin{array}{l}\text { Organizational agility refers to the ability of flexibility } \\
\text { to environmental changes by setting up products and } \\
\text { delivering faster and more inclusive services to achieve } \\
\text { sustainable competitive advantage }\end{array}$ \\
\hline Matthiae \& Richter (2018) & $\begin{array}{l}\text { It refers to the companies responses to environmental } \\
\text { changes as easily as possible. For example, organizatio- } \\
\text { nal agility consists of two components: sensitivity and } \\
\text { response. }\end{array}$ \\
\hline Li \& Holsapple (2018) & $\begin{array}{l}\text { Agility is defined as being able to identify market chan- } \\
\text { ges and take timely action and provide new solutions to } \\
\text { deal with a dynamic and complex environment. }\end{array}$ \\
\hline
\end{tabular}

Source: Own elaboration. 
Many authors have emphasized that organizations consider agility as an objective (Tallon et al. 2018). The characteristics of agile organizations identified in previous research include flexibility, accountability, change culture, speed, integration and low complexity, high quality and customized products, and mobilization of core skills (Baškarada \& Koronios 2018). Most researchers have defined agility as the capacity which requires the active exploitation of benefits and opportunities and positive facing with competitive threats all of which are caused by frequent, sometimes large, and unpredictable changes. Therefore, the lack of agility can lead to significant real losses and the loss of opportunities (Qin \& Nembhard 2010).Van et al. identified 6 categories of factors that require organizational agility: social/legal, business network, competitive environment, customer needs, technology and internal processes (Matthiae \& Richter 2018). Although there is a broad consensus that organizational agility is extremely needed to achieve sustainable competitive advantage, there is no consensus on organizational agility or how to evaluate and improve it (Bashkort \& Coron 2018). A number of factors, including strategy, structure, abilities, employee and leadership may influence organizational agility in different ways (Baškarada \& Koronios 2018). Previous researchers suggest that organizational agility has a positive impact on performance (Cegarra-Navarro et al. 2016). In this research, organizational agility variables of Sharifi and Zhang model (2000) have been used which include: 1) accountability that refers to the ability to detect rapid changes, react to and use them; 2) competence/ qualification that represents the ability in obtaining the objectives and achievements of the organization; 3) Flexibility that is the ability to guide various processes and achieve different goals with the same features, and 4) Speed that is the ability to perform activities in the shortest possible time (GhalichKhani \& Hakkak 2016).

\subsection{Cooperative Management}

Cooperative management (also called "participatory management") is a kind of management style whose main characteristic is frequent use of group decision making. This style is quite the opposite of self-centered management style; in cooperative style it is often believed that this way people work emotionally well - sometimes it is called democratic management(Evans \& Guthrie 2006).

According to the World Bank, cooperative management is the sharing of duties, rights, and responsibilities among the primary stakeholders, especially the nation state and local communities (a report prepared by the World Bank regarding the International Workshop on Community-Based Natural Resource Management). According to the United Nations Food and Agriculture Organization (FAO), cooperative management is defined as a partnership agreement between government and the local community of resource users - and maybe agents like nongovernmental organizations, research institutes, and other stakeholders of resources - to share authority and responsibility for managing some resource (FAO Fisheries and Agriculture Department).

Employee involvement enables the organization to have a better insight about the way of functioning and where it can potentially make improvements that would be beneficial for both, the organization and the employees. There are many studies providing evidence that the employee involvement affects the organizational performance. Also, employee empowerment is considered an important contributor to organizational success. Much ef- 
fort has been made to test the direct relationship between the level of employee empowerment and employee performance, and also, the job satisfaction and commitment. The findings show that there is a significant difference between the employee performance before and after the implementation of empowerment program. Among many dimensions of empowerment, delegation of authority has the strongest effect in improving the employee performance (Sofijanova \& Zabijakin-Chatleska 2013).

Jones and Kato argue that membership in offline teams results in enhanced enterprise performance. According to their estimates, team membership leads to rejection rates improving by about $27 \%$. These findings provide evidence that the introduction of (and membership in) teams will produce more trust by employees in management, improved goal alignment between managers and employees and thus enhanced discretionary effort and attention to quality (Sofijanova \& Zabijakin-Chatleska 2013).

Cooperative management means employee engagement in decision making process, inviting all people to take on individual responsibility with the aim of increasing the quality of their services and products, and rewarding employees` behavior which, from the managers' point of view, every moment satisfies the clients and improves the performance of the organization (Jahanian 2009). Cooperative management is not a simple mechanical technique that easily brings about quick results. Management process is a complicated process which requires great effort and much activity to be effectively implemented. In an article entitled "organizational dynamics", Rosabeth Moss Kanter has investigated issues and problems associated with the implementation of cooperative management plan. He has pointed out that cooperative management failures are often caused by too much emphasis on "being cooperative" and too low emphasis on "management". With this important point in mind, now we deal with some issues of cooperative management. Evidence obtained over 50 years of investigating the performance demonstrate firmly and clearly the effectiveness of management. We can observe the effective patterns of organizational learning through cooperative management in initial and basic research by Hawthorn in 1930s, the classic work by Lewin et al in 1940s and 1950s in Harwood, the study by Mark Frohman in R. G. Burry in 1070s, and Keithley Instruments in 1980s.

\subsection{Employee Empowerment}

In today's competitive world, one of the key tools for making changes in organization, its survival and achieving its goals and missions is human element (Ghafuri \& Mansouri 2014). Since human resources are the most valuable source of production and capital and the source of competitive advantage and the creation of basic capabilities in each organization, one of the most effective ways to achieve competitive advantage in the current situation is the use of more efficient employees in the organization (Ghafuri \& Mansouri 2014). There is a direct relationship between human capital and productivity in any organization. One of the major concerns of successful businesses in the world is the educated and skilled human capital that can change the organization. A successful organization consists of individuals who are compatible with the organizational culture, ideas and objectives of the organization and, through using experience, knowledge and teamwork in their organization, can lead to the progress of it (Horabadi Farahani \& Salimi 2015). 
The defenitions of emplowerment itself vary widely across scholars.Some of these definitions are given in Table 2.

Table 2

Some definitions of employee empowerment

\begin{tabular}{|c|c|}
\hline Author(s) & Conceptualization of Employee empowerment \\
\hline Baird \& Wang (2010) & $\begin{array}{l}\text { "The basic objective of empowerment is redistribution } \\
\text { of power between management and employees most } \\
\text { commonly in the form of increasing employee authority, } \\
\text { responsibility, and influencing commitment" }\end{array}$ \\
\hline Fernandez \& Moldogaziev (2013) & $\begin{array}{l}\text { employee empowerment is a relational construct that } \\
\text { describes how those with power in organizations share } \\
\text { power, information, resources and rewards with those } \\
\text { lacking them. }\end{array}$ \\
\hline Ghafuri \& Mansouri (2014) & $\begin{array}{l}\text { Employee empowerment includes a collection of sys- } \\
\text { tems, approaches, and measures which are used through } \\
\text { development of people capability and competency for } \\
\text { improving and increasing productivity, excellence, } \\
\text { and prospering the organization and human resources } \\
\text { considering organizational }\end{array}$ \\
\hline Oloko \& Ogutu (2017) & $\begin{array}{l}\text { This is a common theme that emphasizes the power of } \\
\text { confident people, passionately committed to meaningful } \\
\text { goals, acting in accordance with own higher values, ta- } \\
\text { king risks and demonstrating imitativeness and creativity } \\
\text { in the service of these goals }\end{array}$ \\
\hline Baird \& Munir (2018) & $\begin{array}{l}\text { Employee empowerment involves the delegation of deci- } \\
\text { sion making authority to lower levels in the organisational } \\
\text { hierarchy, with employees provided with the autonomy to } \\
\text { make day-to-day decisions about job-related activities }\end{array}$ \\
\hline Idris \& Coughlan (2018) & $\begin{array}{l}\text { An employee empowerment approach is composed } \\
\text { of practices aimed at sharing information, job related } \\
\text { knowledge and authority with employees }\end{array}$ \\
\hline
\end{tabular}

Source: Own elaboration.

Many studies empowerment as intrinsic task motivation or motivation reflective of the person environment fit (Gilaninia 2012). In other literature, empowerment has been defined as perceptions and as commitment-based designs. Researchers have also defined empowerment in terms of job structure the transfer power or authority (Zimmerman 1990). Empowerment of employees means creat collection of required capacity in human resources for enable them to creating added value in organizaion and role playing and responsibilities are responsible in the organization, with efficiency and effectiveness (Burk 1986).

The first definitions of empowerment were presented by Conger and Kanungo in 1988. They believed that empowerment should be studied as motivational and communicational factor (Horabadi Farahani \& Salimi 2015). The two main types of employee empowerment, namely structural empowerment and psychological empowerment, have been discussed in 
literature. While structural empowerment refers to organizational mechanisms that make the board of directors transfer responsibility and decision power from management to employees, psychological empowerment defines the increase of the incentive for work or the increase of self-efficacy emotions by satisfying the need of employees. From a structural point of view, empowerment eliminates the barriers between managers and subordinates, and provides better communication and information sharing that enables employees to participate in the decision-making process. On the other hand, psychological empowerment usually involves the sense of belonging of employees to the organization where they work (Idris \& Coughlan 2018). Finally, existing literature suggests that employee empowement leads to positive performance (Parkhurst et al. 2013)

\section{HYPOTHESIS DEVELOPMENT AND CONCEPTUAL MODEL}

Participation is considered as a means of enhancement, and it can be claimed that the use of employee participation and cooperation results in objectives such as creating a sense of attachment among employees, being aware of employees` opinions, and cultivating (fostering) talents; also, adoption and implementation of cooperative management in the presence of participation prerequisites will bring about fruitful results for the individual and organization (Davis \& Newstrom 1989). Further, cooperative management has various benefits including faster response to planning, determination of strategies and solutions, enhancement of commitment and accountability in implementing decisions, more innovation, appropriate use of opportunities, and feeling of dignity and value among employees (Afjeh 2003). Organizational agility enables the organizations to successfully perform a series of specific tasks. Further it enables the organizations to effectively manage opportunities and risks across business activities(Ardichvili et al. 2003). Abtahi and Abbasi (2007) investigated the association between cooperative management (with emphasis on suggestion system) and employee effectiveness. The results suggested a significant association between cooperative management dimensions (participation in goal-setting, decision making, problem solving, and providing constructive suggestions) and employee effectiveness dimensions. Therefore, it is necessary to know about the impact of cooperative management system on the agility of the studied organization.

H1: Cooperative management of employees has an positive effect on organizational agility.

Traditional cooperative management is concerned with decision making in which the government delegates (or transfers) part of its power (or authority) to others. The term "cooperative management" has been applied broadly to refer to various arrangements with different levels of sharing of authority - for collaborative decision making by the government and user groups as regards area or a set of resources. There is no standard definition for fisheries sector or other natural resource sectors. One of the main components of cooperative management is, in addition to resource management, the relationships existed among regulators, users, and other stakeholder individuals. Governance systems which combine state control with decentralized and local decision making and accountability, make a combination of strengths and lessen their weaknesses (Carlsson \& Berkes 2005). In his study, Rahmati (2011) examined the association of cooperative management 
and empowerment with employee productivity in Rafsanjan Pistachio Company (Rahmati 2011). Results of the analyses demonstrated that empowerment plays a mediating role between cooperative management and productivity. In a research, Tolouei Far (2011) investigated the relationship between cooperative management and psychological empowerment of employees of Medical Services Insurance Organization in Tehran province (Tolouei Far 2011). Findings indicated that cooperative management does not indirectly affect on psychological empowerment through organizational conditions, instead this relationship is established directly. In his study entitled "The Investigation of The Relationship between Cooperative Management and Empowerment of Teachers of Girls High Schools in Kerman in the School Year 2013-2014", Tavakoli (2013) concluded that there is a positive high relationship between cooperative management and teacher empowerment (Alitavakoli 2013). Iranzadeh and Zanjani (2013) conducted a study entitled "A survey of the Association of Cooperative Management with Empowerment and Mental Health of Female Teachers of Girls High Schools in Tabriz". Results indicated that cooperative management is significantly associated with empowerment and mental health(Iranzadeh 2010). Further, among all management dimensions (decision making, communications, leadership, structure, and control) only the component of decision making was significant, which predicted employee empowerment and mental health. In a study entitled "The Impact of Participation in Decision Making and Reduction of Job Pressure", (Jackson 1983) found that participation of individuals in decision making as a decisive factor in reducing job pressures. Also Stumpf (2001) conducted a study on the effect of cooperative and traditional management on job satisfaction of nurses, patients` satisfaction, and the rate of nurses` interest in and commitment to nursing profession. Results showed that in the areas where cooperative management was implemented, the degree of nurses` job satisfaction and patients` satisfaction as well as the degree of nurses interest in and commitment to continuing the nursing profession and staying at their job increased. The researcher states that the implementation of cooperative management results in decreased costs, better delivery of work with higher quality, and increased motivation among the employees and thus, leading to job satisfaction and organizational commitment.

\section{H2. Cooperative management of employees has an positive effect on employee empowerment.}

Quick environmental changes threaten the survival of many organizations, and the global economy is pushing ahead with regional economic pressures. New information technology media, consumer world cultures, the emergence of global standards, and the possibility to share costs are effective environmental changes existing in today`s organizations. The survival of many organizations is threatened by inconsistency or incompatibility with environmental changes (Abtahi \& Abbasi 2007). Vast environmental changes in today`s turbulent world necessitates the flexibility of organizations so as to ensure their survival. According to Goodarzi and Gaminian (2002) empowering and giving freedom of action to employees is an essential strategy for increasing performance and ensuring survival in today`s organizations.

One can view organizational agility (from now, OA) as organizational performance state in terms of adaptability and flexibility, which can be attained by means of the organization`s activities. Particularly, from a process-based viewpoint, OA is defined as a set of processes make it possible for an organization to sense changes and respond to them 
in an efficient, effective, timely, and cost-effective way, both in external and internal atmospheres. According to Seo and Paz (Seo \& La Paz 2008), sensing is the ability of an organization in detecting, capturing as well as interpreting organizational opportunities. On the other hand, as Gattiker et al(Gattiker et al. 2005) and Oosterhout et al (van Oosterhout et al. 2006)a propose, responding refers to the ability of an organization in mobilizing and transforming resources in order to react the opportunities it senses. As Overby et al (2006) propose, in order for OA to be obtained optimally, the two capabilities must be in good alignment.

In his study, Azizi Asl et al. (2015) investigated the association between psychological empowerment of human resources and organizational agility from the viewpoint of employees of Shiraz University. Results suggested that employee psychological empowerment and the University`s organizational agility were higher than average. Also, there is a significant positive association between psychological empowerment and its dimensions and organizational agility; and psychological empowerment is the significant predictor of organizational agility ( Azizi Asl et al. 2015). Among all dimensions, the three dimensions namely significance, effectiveness, and right to choose would account for $51 \%$ of organizational agility variance. Reviewing the impact of organizational agility on product development, Alzoubi et al. (2011) examined the impact of employee empowerment on organizational agility and confirmed the positive impact of this relationship (Alzoubi et al. 2011). Heydari (2013) investigated multiple relationships of organizational learning, organizational agility characteristics, and excellent organizational empowerment based on the viewpoints of faculty members at State universities of Isfahan. Findings of this research showed that there was a positive and significant relationship between organizational agility and excellent organizational empowerment. Additionally, the results of regression analysis showed that there is a relationship between organizational learning aspects, organizational agility characteristics and excellent organizational empowerment (Heydari 2013). The results of the research conducted by Horabadi-e-Farahani and Salimi (2015) entitled "the relationship between employee empowerment and organizational agility: case study in Azarab Industries," shows that there is a significant positive correlation between employees empowerment and organizational agility in Azarab Industries Co. (Horabadi Farahani \& Salimi 2015). On the other hand, the research of Muduli (2017), entitled "the Agility of Labor: Investigating the Role of Organizational Styles and Psychological Empowerment," has confirmed that there is a positive and significant relationship between empowerment and organizational agility (Muduli 2017).

\section{H3. Employee empowerment has an positive effect on organizational agility.}

Muduli (2017) showed that an environment that encourages teamwork has the most influence in promoting agility, followed by programs that address reward systems, employee involvement, organizational learning and training, and information systems. In addition, the study found that agility is fostered by the psychological empowerment variable of impact, followed by self-determination, meaning, and competence. GhalichKhani \& Hakkak (2016) studied a model for measuring the direct and indirect impact of business intelligence on organizational agility with the mediating role of empowerment. Rezaei et al. (2015) wrote a thesis entitled "Investigating the Relationship of Cooperative Management with Justice Perception and Empowerment of Employees of Supportive Institutions 
(A Case Study of Imam Khomeini Relief Committee in Ardabil Province). Results indicated that cooperative management is significantly associated with empowerment and organizational justice perception of employees. On the other hand, the two components (goal setting and decision making) are involved in predicting the organizational justice perception, and also the component "goal setting" with coefficient is involved in explaining and predicting employee empowerment. Ghafuri et al. (2014) believes that there is positive significant relationship between human capital, structural capital and relational capital in one hand, and organizational agility on the other hand. This result is also confirmed by Ghafuri \& Mansouri (2014). Kirkman \& Shapiro (2001) in a research titled "The impact of team members' cultural values on productivity, cooperation, and empowerment in self-managing work teams" resulted that team members cultural values have a significant positive impact on employeees empowerment. Therefore, theoretical and empirical evidences indicate that impowerment has a mediator role between cooperative management and organizational agility.

H4. Employee empowerment mediates the association between cooperative management and organizational agility.

The conceptual model of the research is presented in Figure 1.(Ghalichkhani \& Hakkak 2016; Horabadi Farahani \& Salimi 2015)

Figure 1

The conceptual modeSource: Own elaboration.

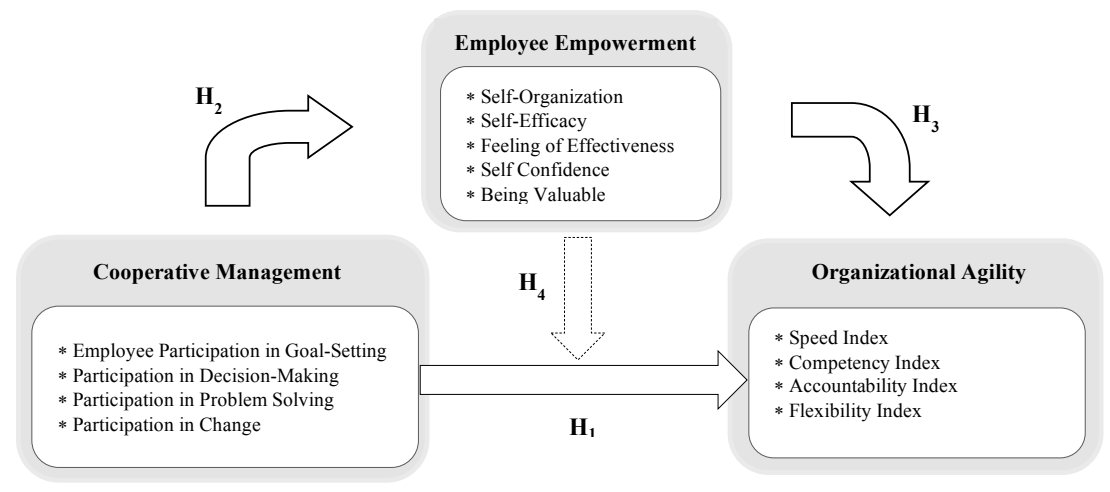

Source: Own elaboration. 


\section{RESEARCH METHOD}

\subsection{Population and Sampling}

Statistical population of the current study consisted of all employees of Tabriz \& Suburbs Bus Company $(\mathrm{N}=650)$. Convenience method was applied in this research. Cochran`s formula was used to determine total size of the sample from the population as follows. To determine the sample size by using Cochran`s formula, you need to know the population size. This calculation is done with a $5 \%$ error level $(q=p=0.5, t=1.69, d=0.05, N=650)$. The related formula is as follows.

$$
\text { 1) } n=\frac{N t^{2} p q}{N d^{2}+t^{2} p q}=\frac{650 *(1.96)^{2} * 0.5 * 0.5}{650 * 0.05^{2}+1.96^{2} * 0.5 * 0.5}=242
$$

Where, $\mathbf{n}$ : sample size, $\mathbf{N}$ : population size, s: population variance, p: probability of having the desired attribute, q: probability of not having the desired attribute, T-student: which is 1.96 at $5 \%$ level for a population higher than 120 people.So, a total of 243 people $(n=24)$ were selected from the population as the research sample through Cochran`s formula. Considering the above-mentioned formula, the sample size was estimated to be 242 people. A total of 250 questionnaires were distributed among the subjects, of which 242 correct and usable questionnaires were tested.

\subsection{Variables Measurement}

Data collection tool in the present study was a questionnaires. The research questionnaire consisted of three parts namely a cover letter, demographic information, and specific questions. In the first part under the title of cover letter, in addition to expressing the research title, the purpose of data collection through questionnaire as well as the necessity of sincerely cooperation of respondents in completing the questionnaire were clearly explained. Demographic part of the questionnaire included questions as regards general specifications of the respondents such as gender, marital status, educational status, age, work experience, and employment type. And the last part consisted of specific questions on independent and dependent variable of the research.

This part consisted of 17 questions for measuring cooperative management based on Ranjbar and Labbaf s model (2007), 29 questions for measuring organizational agility according to Sharifi and Zhang`s model, and 19 questions for measuring employee empowerment on the basis of Spritzer`s model. Data collection tool was a researcher-made questionnaire. A five-item Likert scale was used in designing the questionnaire $(1=$ strongly disagree, 2 = disagree, 3 = indifferent, 4 = agree, 5 = strongly agree).

\subsection{Statistical Analysis Methods}

Prior to performing any analysis on the collected data and statistical inference, one must first ensure the reliability and validity of the measurement tool. reliability of the questionnaire was measured by Cronbach`a alpha test. There are multiple methods available for 
measuring the validity of the questionnaire; Given that the research variables are composed of several dimensions (components), Confirmatory Factor Analysis has been applied in this research.

Partial Least Squares (PLS) method was used for testing the research model. To establish an association between dependent and independent variables, PLS creates new explanatory (independent) variables. Unlike Structural Equation Modeling (SEM) based on covariance, PLS method focuses on the highest variance of dependent variables explained by independent variables, instead of reproduction of empirical covariance matrix. Similar to SEM, PLS consists of a structural part indicating the association between latent variables, and a measurement component reflecting the association of latent variables and their markers. In PLS, measuarement models are divided into two groups (reflective and formative) based on their perspectives towards latent variable. In reflective models, the latent variable is considered a predictor variable, that is the observed variables are regressed to the latent variable. Here, it is assumed that observed changes in the observed variable are caused by the latent variable. However, in formative model, the observed variables are independent variables and their effects would cause change in the latent variable, and thus in this case the latent is regressed to the observed.

Moreover, following the the evaluation of measurement model and structural mod$\mathrm{el}$, it is necessary to assess the overall model fit by using appropriate criteria. Generally speaking, in the current study, available criteria including Chi square (2\%), Root Mean Square Error of Approximation (RMSEA), Comparative Fit Index (CFI), Goodness of Fit Index (GFI), and Adjusted Goodness of Fit Index (AGFI) were used. Application of PLS is one of the important advantages the most important of which are estimation of multiple relationship, measurability of latent variables, calculation of measurement error, the capability of examining collinearity, and testing spurious and unreal relationships of the model structures (Davari and Rezazadeh, 2013). Then the research hypotheses are tested by using SPSS and PLS AMOS.

\section{RESULTS}

\subsection{Demographic Characteristics of the Respondents}

Analysis of the demographic characteristics of the statistical sample members is shown in Table 3.

As shown in Table 3,97.1\% of the respondents are male and $2.9 \%$ are female. On the other hand, individuals under 30 years of age (with $40.5 \%$ ) compose the most part of the statistical sample, while individuals over 50 years of age (with 12\%) compose the least part of it. Individuals holding a bachelor`s degree (with 51.7\%) compose the most part of the statistical sample, while individuals holding a diploma and under diploma degree (with $1 \%$ ) compose the least part of it. Finally, the highest work experience (34.3\%) belongs to "under 5 years of work experience" group, while the lowest work experience $(5.4 \%)$ belongs to " $15-20$ years of experience" group. 
Table 3

Demographic characteristics of the respondents

\begin{tabular}{|l|l|c|c|}
\hline \multicolumn{1}{c}{$\begin{array}{c}\text { Demographic } \\
\text { Characteristics }\end{array}$} & \multicolumn{1}{|c|}{ Classes } & Number (N) & Percent (\%) \\
\hline \multirow{5}{*}{ Gender } & Male & 235 & 97.1 \\
\hline \multirow{5}{*}{ Age } & Female & 7 & 2.9 \\
\hline \multirow{5}{*}{ Educational Status } & Under 30 years & 98 & 40.5 \\
\cline { 2 - 4 } & $30-40$ years & 62 & 24.6 \\
\cline { 2 - 4 } & $40-50$ years & 29 & 21.9 \\
\cline { 2 - 4 } & over 50 years & 1 & 12 \\
\cline { 2 - 4 } & Diploma & 56 & 0.4 \\
\cline { 2 - 4 } & Associate Degree & 125 & 23.1 \\
\cline { 2 - 4 } & Bachelor`s Degree & 58 & 51.7 \\
\cline { 2 - 4 } & PhD & 2 & 24.0 \\
\hline \multirow{5}{*}{ Work Experience } & Less than 5 years & 83 & 0.8 \\
\cline { 2 - 4 } & $5-10$ years & 61 & 34.3 \\
\cline { 2 - 4 } & $10-15$ years & 46 & 25.2 \\
\cline { 2 - 4 } & $15-20$ years & 13 & 19 \\
\cline { 2 - 4 } & More than 20 years & 39 & 5.4 \\
\hline
\end{tabular}

Source: Own elaboration.

\subsection{Validity and Reliability of the Questionnaire}

The complete model of the structural equation consists of two components, namely measurement model and structural model. Prior to entering the test phase of the research conceptual model, first of all, it is necessary to ensure the accuracy of the measurement model. In measurement model, the relationship between latent and observed variables is examined. There are various methods for examining the fitting of the model, however the method that comprehensively examines the fitting of the measurement model is the use of PLS (Partial Least Squares) in which three criteria including construct validity, discriminant validity, convergent validity, and reliability are used for examining the fitting of measurement models. Construct validity means the capability of measuring the research variables through questionnaire, which is tested by using Confirmatory Factor Analysis. Figure 2 and Table 4 shows the results of this method, including factor loadings. 


\section{Figure 2}

Initial measurement model in the mode of standard coefficient estimation by deleting questions

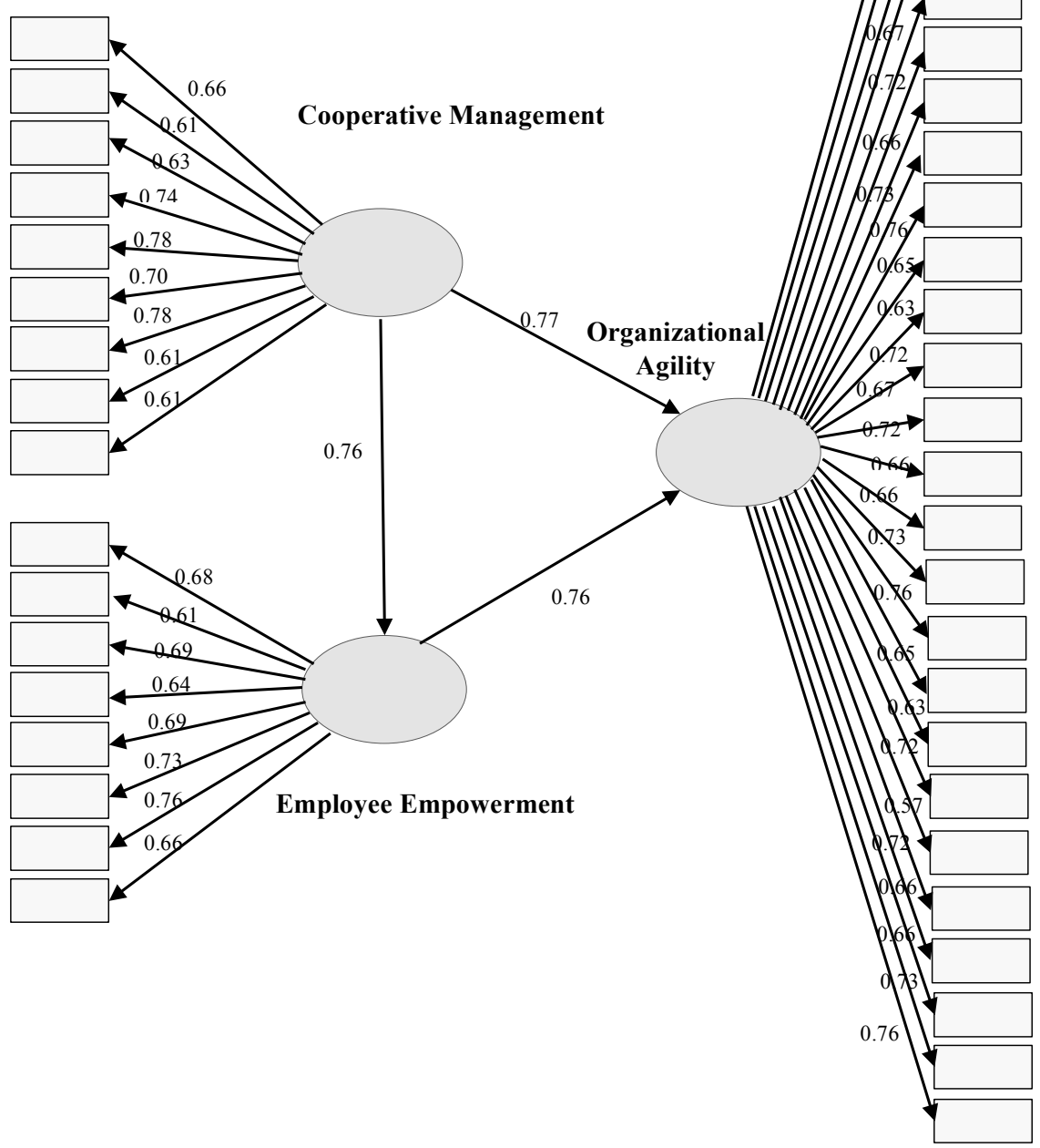

Source: Own elaboration. 


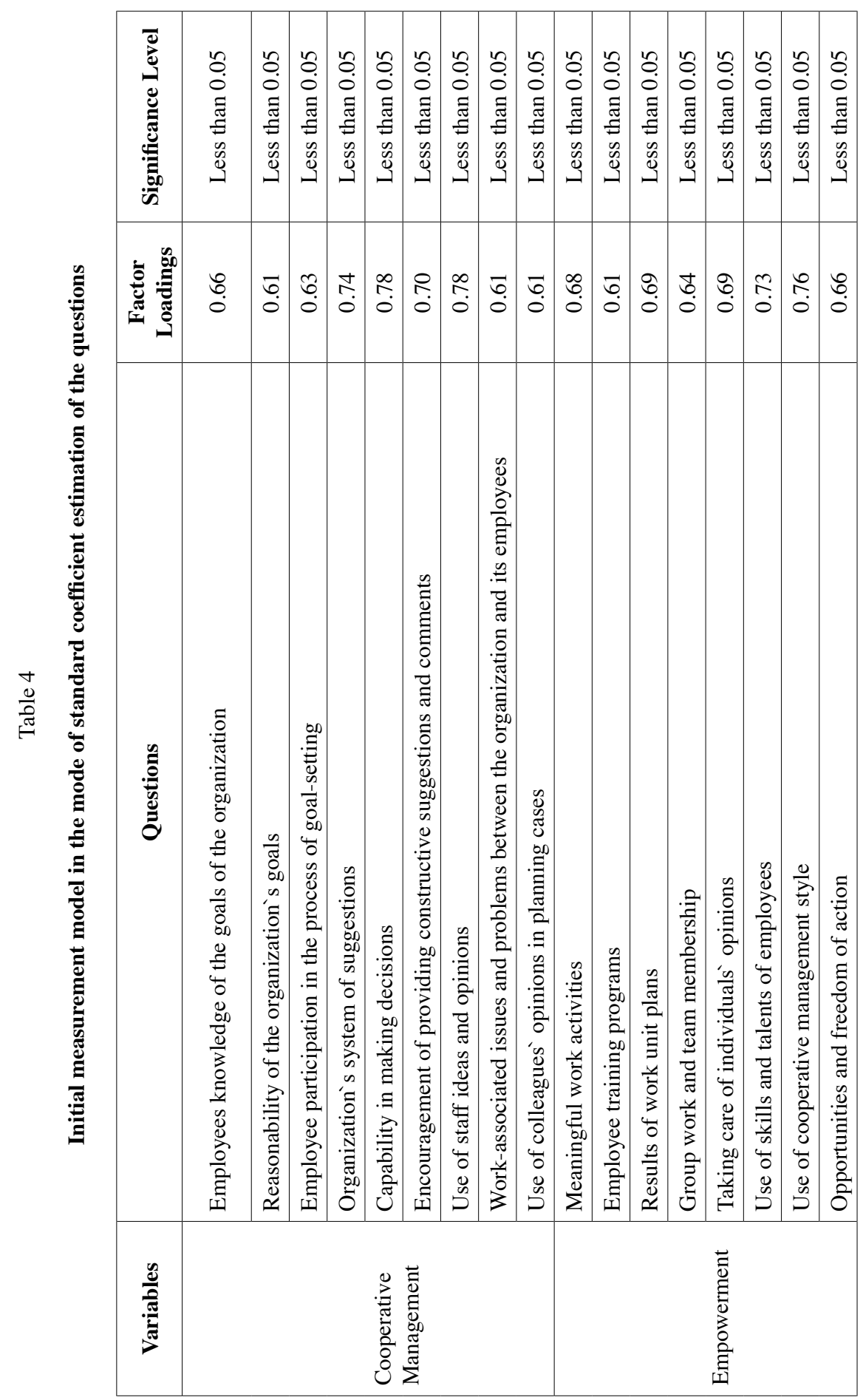




\section{¿)

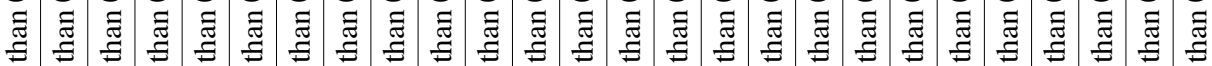

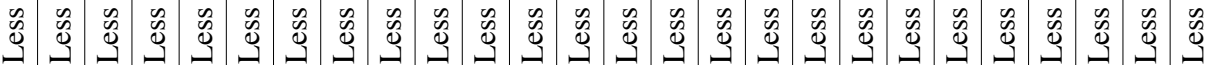

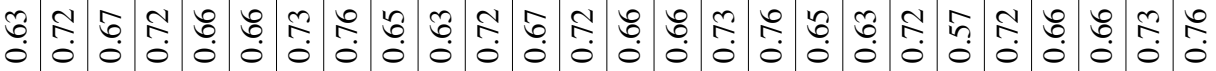

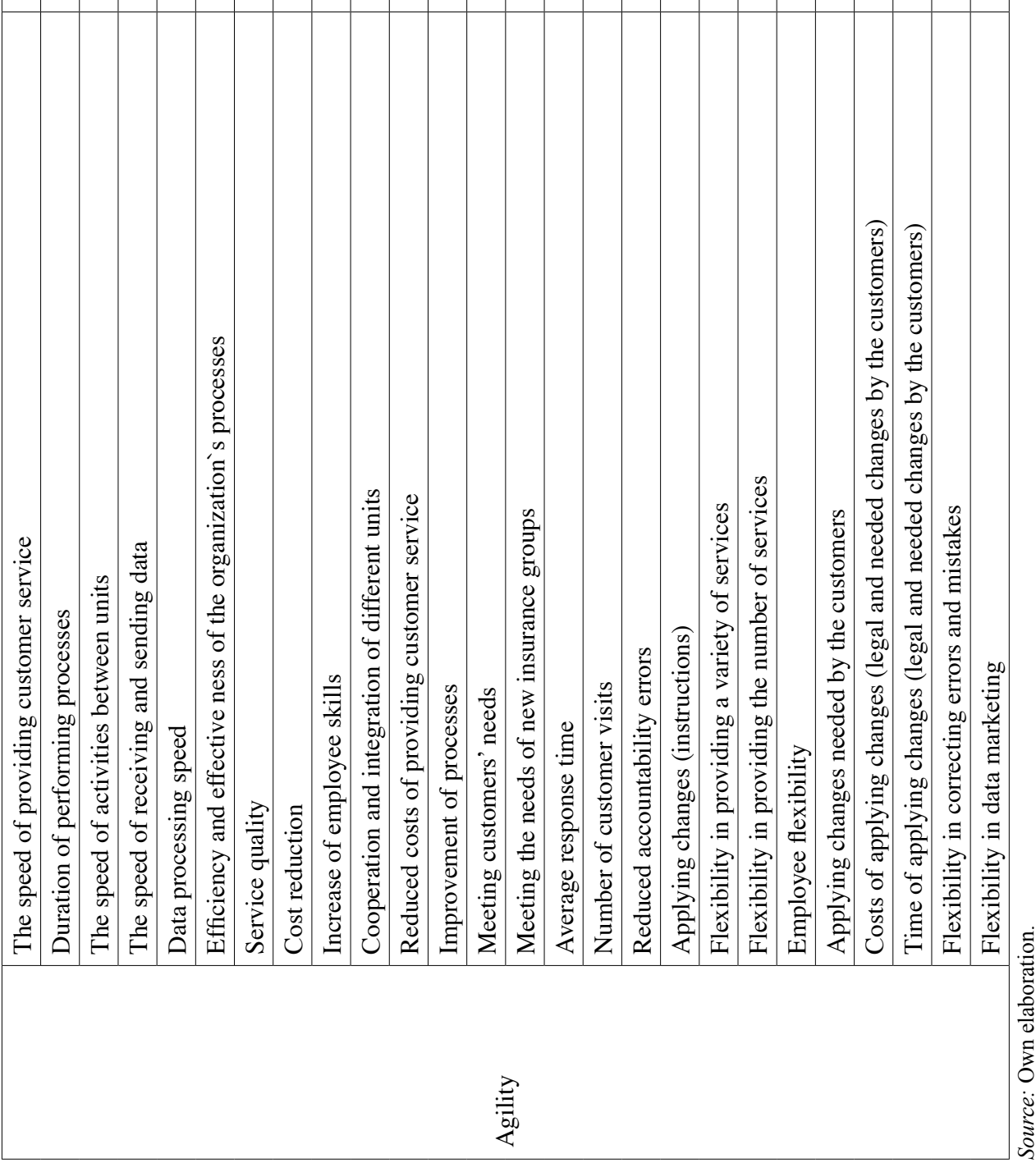


If the factor loading of the questions is less than 0.6 , then the desired question is removed; in the above Table, the questions whose factor loading is less than 0.6 are removed. Therefore, the following questions are removed:

questions $1,3,4,6,7,8,9,12,13,14,15,16$ of the variable "cooperative management"; questions $1,3,4,6,7,8,9,10,11,12$, and 15 of the variable "empowerment"; and questions $6-16$ and 26 of the variable"organizational agility".

In addition to Structure Validity, Discriminant Validity was studied in this research. Discriminant Validity means that items of each structure will finally provide a proper separation in terms of measurement as compared to other structures of the model. This validity is measured using Average Variance Extracted index. Average Variance Extracted shows the degree of correlation of a structure with its indicators, and the greator the correlation, the better the fitting of the model will be. Additionally, the reliability was examined on the basis of Cronbach`a alpha. PLS provides a more modern criterion than Cronbach`s alpha called Composite Reliability in which the reliability of the structure is calculated not in absolute terms, but in relation to the correlation of their structures with each other. In the present study, Composite Reliability was used for measuring Convergent Validity (Davari $\&$ Rezazadeh, 2013). The results of different indicators of validity and reliability are presented in the Table 5.

Table 5

The results of discriminant validity, convergent validity, and reliability

\begin{tabular}{|l|c|c|c|c|}
\hline \multicolumn{1}{|c|}{ Variables } & $\begin{array}{c}\text { Number of } \\
\text { Questions }\end{array}$ & $\begin{array}{c}\text { Average Variance } \\
\text { Extracted (AVE) }\end{array}$ & $\begin{array}{c}\text { Composite } \\
\text { Reliability (CR) }\end{array}$ & $\begin{array}{c}\text { Cronbach`s } \\
\text { Alpha } \\
\text { Coefficient }\end{array}$ \\
\hline Cooperative Management & 17 & 0.69 & 0.89 & 0.814 \\
\hline Organizational Agility & 29 & 0.67 & 0.93 & 0.795 \\
\hline Employee Empowerment & 19 & 0.65 & 0.87 & 0.914 \\
\hline
\end{tabular}

Source: Own elaboration.

Discriminant Validity will be established if only the value of AVE is greater than the critical value (0.5). Further, there are three prerequisites for the fulfillment of Convergent Validity as follows: 1) the value of Composite Reliability must be greater than 0.7 ; ) the value of AVE must be greater than 0.5; and 3) the value of Composite Reliability must be greater than AVE. If the value of Composite Reliability for each structure is higher than 0.7 , it indicates a proper internal consistency for measurement models; the value of 0.6 also implies a lack of reliability. Finally, experts in the area consider the standard value for Cronbach`s alpha to be 0.7 (Davari \& Rezazadeh, 2013). Therefore, according to Table 6 and standard values for the desired indicators we can conclude that Discriminant Validity, Convergent Validity, and Composite Reliability exist for all the variables "cooperative management, organizational agility, and e,ployee empowerment", and overally, research measurement models are in a desirable situation.

One way of determining the discriminant validity of the structures is through Fornell \& Larcker matrix in which discriminant validity is at an acceptable level if the value of the 
extracted variance for each structure is more than the shared variance between the structure that structure and other structures (that is, the square of correlation coefficients between the structures) in the model (Fornell \& Larcker, 1981, quoted by davari and Rezazadeh, 2013). We take the square root of AVE values presented in Table 6 and 7, and in Unit Matrix in Correlation Table we put latent variables in place of 1 numbers.

Table 6

\section{Latent variable correlation}

\begin{tabular}{|c|c|c|c|}
\hline & $\begin{array}{c}\text { Organizatio- } \\
\text { nal Agility }\end{array}$ & $\begin{array}{c}\text { Cooperative } \\
\text { Management }\end{array}$ & $\begin{array}{c}\text { Employee } \\
\text { Empowerment }\end{array}$ \\
\hline Organizational Agility & 1 & & \\
\hline Cooperative Management & 0.77 & 1 & \\
\hline Employee Empowerment & 0.76 & 0.76 & 1 \\
\hline
\end{tabular}

Source: Own elaboration.

Table 7

Fornell \& larcker test

\begin{tabular}{|c|c|c|c|}
\hline & $\begin{array}{c}\text { Organizational } \\
\text { Agility }\end{array}$ & $\begin{array}{c}\text { Cooperative } \\
\text { Management }\end{array}$ & $\begin{array}{c}\text { Employee } \\
\text { Empowerment }\end{array}$ \\
\hline Organizational Agility & 0.81 & & \\
\hline Cooperative Management & 0.76 & 0.83 & \\
\hline Employee Empowerment & 0.76 & 0.77 & 0.81 \\
\hline
\end{tabular}

Source: Own elaboration.

Given the values of the above table, the value of the structure's extracted variance is 0.81 , which is greater than both the value of the shared variance between organizational agility and cooperative management (0.77) and the value of the shared variance between organizational agility and employee empowerment (o.76) and accordingly, the degree of divergence of organizational agility is acceptable. The variance of cooperative management structure is 0.83 , which is greater than both the shared variance between cooperative management and organizational agility $(0.77)$ and the shared variance between cooperative management and employee empowerment (also 0.77), and thus confirming the divergence of cooperative management. The variance of employee empowerment structure equals 0.81 , which is greater than both the shared variance between employee empowerment and organizational agility (0.76) and the shared variance between employee empowerment and cooperative management $(0.77)$, and thus confirming the convergence of employee empowerment. 


\subsection{Testing Measurement Model Quality}

In case the value of variation coefficient is greater than 0.35 , the power of model in prediction is high. The results is presented in Table 8.

Table 8

\section{CV com test}

\begin{tabular}{|c|c|}
\hline Agility & 1 - SSE/SSO \\
\hline Cooperative Management & 0.43 \\
\hline Empowerment & 0.34 \\
\hline Agility & 0.30 \\
\hline
\end{tabular}

Source: Own elaboration.

\subsection{Research Model Estimation}

Figures 3 and 4 demonstrate research model with latent and observed variables therein in the form of research structural model, along with the model for testing the significance of the hypotheses.

Figure 3

\section{Research structural model}

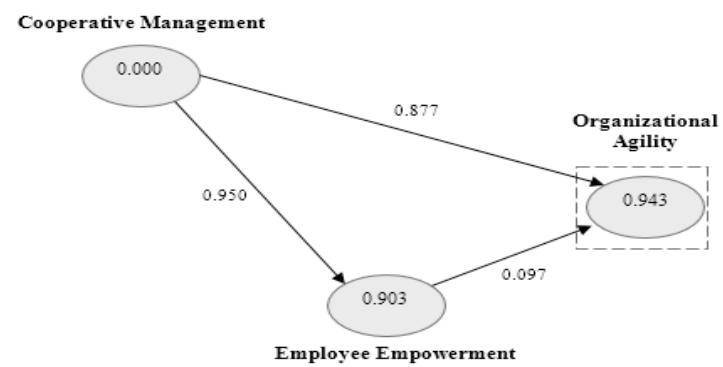

Source: Own elaboration.

In PLS, following the examination of the fitting of measurement models, the next step is to deal with the fitting of the structural model. One main criterion, among others, for examining the fitting of the structural model is Determination Coefficient $\left(R^{2}\right) . R^{2}$ is a criterion that shows the effect of an exogenous variable on an endogenous variable, whose value is only calculated for endogenous constructs of the model. As for endogenous constructs, the value of this criterion is zero. Three values $(0.19,0.33,0.67)$ are considered as a criterion for $\mathrm{R}^{2} \mathrm{~s}$ weak, medium, and strong values respectively. According to Figure 3, the value of $\mathrm{R}^{2}$ for the model's endogenous variables including organizational agility and employee empowerment are 0.943 and 0.903 , respectively. So, given the criterion values, the model all together has a good structural fit. 
Figure 4

Model for significance test of the research hypotheses

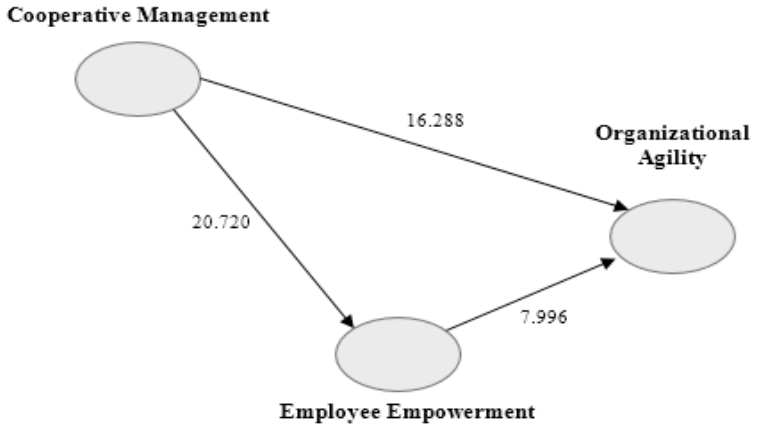

Source: Own elaboration.

Table 9

Estimation of path coefficients in structural equation modelling

\begin{tabular}{|l|c|c|c|}
\hline \multicolumn{1}{|c|}{ Casual Path } & Path Coefficients & Significance Level & Result \\
\hline $\begin{array}{l}\text { Cooperative Management and } \\
\text { Organizational Agility }\end{array}$ & 0.877 & 16.288 & Confirmed \\
\hline $\begin{array}{l}\text { Cooperative Management and } \\
\text { Employee Empowerment }\end{array}$ & 0.950 & 20.720 & Confirmed \\
\hline $\begin{array}{l}\text { Employee Empowerment and Orga- } \\
\text { nizational Agility }\end{array}$ & 0.097 & 7.996 & Confirmed \\
\hline
\end{tabular}

Source: Own elaboration.

The results guggested that there is a positive relationship between employee cooperative management and organizational agility. Since the significance coefficient of employee cooperative management with organizational agility is 16.288 , employee cooperative management would affect organizational agility by $99 \%$ probability. Accordingly, H1 is confirmed. There is a positive relationship between employee cooperative management and employee empowerment. As the significance coefficient of employee cooperative management with employee empowerment is 20.720 , employee cooperative management would affect employee empowerment by $99 \%$ probability, and thus confirming $\mathrm{H} 2$. There is a positive relationship between employee empowerment and organizational agility. Since the significance coefficient of employee empowerment with organizational agility is 7.996 , employee empowerment would affect organizational agility by $99 \%$ probability, and thus confirming $\mathrm{H} 3$.

In order to test the mediating role of employee empowerment, it is essential to determine the direct, indirect, and total impact of the variables. The results are given in Table 10 . 
Table 10

The direct, indirect, and total impact of the variables

\begin{tabular}{|l|c|c|c|}
\hline Variable & $\begin{array}{c}\text { Direct impact on } \\
\text { employee } \\
\text { empowerment }\end{array}$ & $\begin{array}{c}\text { Indirect impact on } \\
\text { employee } \\
\text { empowerment }\end{array}$ & Total impact \\
\hline Cooperative management & 0.95 & - & 0.95 \\
\hline Variable & $\begin{array}{c}\text { Direct impact on } \\
\text { organizational agility }\end{array}$ & $\begin{array}{c}\text { Indirect impact on } \\
\text { organizational agility }\end{array}$ & $\begin{array}{c}\text { Total impact (the } \\
\text { sum of direct and } \\
\text { indirect impact) }\end{array}$ \\
\hline Cooperative management & 0.877 & $0.95 * 0.097$ & 0.969 \\
\hline Employee empowerment & 0.097 & - & 0.097 \\
\hline
\end{tabular}

Source: Own elaboration.

According to the Table 10, given the direct impact of cooperative management on organizational agility which is equal to 0.877 and also the indirect impact of cooperative management on organizational agility that is equal to 0.092 and is carried through employee empowerment, the obtained result shows that employee empowerment influences the relationship between cooperative management and organizational agility; hence, the mediating role of employee empowerment is confirmed.

\subsection{GOF (Goodness of Fit)}

GOF examines the overall prediction ability of the model, and also examines whether or not the tested model has been successful in predicting latent endogenous variables. The average Communality is multiplied by the average $\mathrm{R}^{2}$ and then take its square root. The Results presented in Table 11.

Table 11

\section{Results of GOF}

\begin{tabular}{|c|c|c|}
\hline Variable & Communality & R Square \\
\hline Organizational Agility & 0.67 & 0.95 \\
\hline Cooperative Management & 0.69 & \\
\hline Employee Empowerment & 0.65 & 0.93 \\
\hline
\end{tabular}

Source: Own elaboration.

If GOF indicator is greater than 0.35 , the quality of the model is strong; if it is between 0.19 and 0.35 , the quality of the model is medium; and if it is between 0.02 and 0.19 , the quality of the model is weak. Given the velue obtained from the above relation in which GOF indicator is 0.79 (which is greater than 0.35 ), the model is strong and powerful. 


\section{DISCUSSION}

Changes in management perspectives in the global arena, especially the changes caused by human relations movement, have made the role of human resource management (HRM) more prominent in the success of the organization. However, studies show that along with global changes, managers in Iranian organizations have not paid necessary attention to human resources.

Overally, it can be said that cooperative management in general and employee participation (involvement) in particular in goal setting, decision making, problem solving, and making changes in organizations can have a significant impact on organizational agility. Participation in the management of organizations will make employees show sympathy in enhancing the quality and productivity in all fields and continually increase their social attachment and affiliation towards target groups. Thus, by concluding the above findings we can confirm a major hypothesis as follows: "Emoloyee cooperative management affects organizational agility". The results of this study are consistent with the results obtained by Azizi Asl et al. (2015) and Ranjbar (1988).

Employee empowerment is an important tool in increasing employee productivity, which an organization`s manager must definitely try to implement it across the organization. When tasks are repetitive and boring, the manager can create a friendly, informal and diverse atmosphere so as to bring happiness and more motivation among the employees in the workplace. When tasks are vague, hard, exhausting, and critical, first of all the duties must be specified and then the rewarding must be considered by the manager. And when knowledgeable individuals with independent spirit like to have internal control over their activities, cooperative leadership would be effective. Cooperative management style is the cornerstone and prerequisite of employee empowerment. Therefore, managers should prepare a good platform for the implementation of this style. Human capital is considered the biggest asset of any organization in terms of having the power of thought, creativity, and innovation, because any improvement or progress in technical and organizational systems is carried out by it. Intellectual power and thoughts of employees in the organization serve as latent and stagnant capital; any organization or management that can make the most use of these latent capitals, equally the possibility of growth and development would be at hand for it. Unlike other resources, human resources will not be reduced or depreciated through consumption: the more it it sues thought, the more its ability would improve. On the other hand, participation (cooperation) is one of the extraordinary needs of humans, which is rooted in human nature. Overally, by concluding the above findings we can confirm the hypothesis that "cooperative management affects employee empowerment". The results of the present study are fully consistent with the results of a research by Rezaei Ali Babaloo et al. (2015), Habibi \& Falahati (2004), Rahmati (2011) and Toloui Far (2011).

Agile organizations think far beyond adaptation to changes; they tend to take advantage of potential opportunities in a turbulent environment and gain a steady position due to their own innovations and competencies. Given the flexibility and high power of accountability in agile organizations, creative, innovative, and knowledgeable human resources are of special important. In such organizations, successful identification of competition Basics (speed, flexibility, innovation, quality, and profitability), coherence of resources, and taking appropriate measures in a knowledge environment with rapid changes by providing 
customer-friendly products and services are important. Flexible constructs, multiskill employees, emphasizing on empowerment programs, establishing the culture of innovation and creativity, and the importance of knowledge - based business are among the requirements of agile organizations. The above findings can lead to the confirmation of the hypothesis that "employee empowerment affects organizational agility". The results of this study are fully consistent with the results obtained by Azizi Asl et al. (2015) in his work entitled "Investigating the Relationship between Human Resource Psychological Empowerment and Organizational Agility", and partially consistent with the results of a study by Jakcson (2004) and the results obtained by Fakhimi (2013) in his research entitled "Human Resource Empowerment in order to Improve Organizational Agility".In order to apply cooperative management more extensively, individual preparation level of managers and employees must be enhanced for imolementing this system. These preparations include individuals` career maturity, willingness to participate, responsibility, and having a positive view of subordinates and establishing a good relation with them. Promotion of groupwork culture provides the necessary platform for empowering individuals. According to Drucker (1998), the present age is the age of knowledge-based works. Now the main capital of institutions and organizations is their human resources as knowledge workers, so managers of the organizations, affected by the fluctuating wave of the 21th century, have to rethink and recreate their methods, models, and thoughts concerning employed human resources. So, training will be of great importance in this regard. Changes in management perspectives in the glogal arena, especially the changes brought about by the Human Relations Movement have made the role of human resource management more prominent in the organization`s success. However, studies have shown that along with global changes, managers in Iranian organizations have fialed in paying necessary attention to human resources. If implementation of cooperative management in different ways involves employee participation in decision making, goal setting, problem solving, and changes within the organization by applying participatory methods through offering suggestions, participating in meetings, etc., it will greatly promote innovation, competence, flexibility, empowerment, and in general agility within the organization. Generally speaking, by concluding the above findings we can reach the confirmation of a major hypothesis that "cooperative management affects organizational agility through the mediating role of organizational empowerment.

If participation in different aspects involves the use of opinions and effective cooperation of employees in different processes, it can bring about more employee effectiveness and thus, leading to better performance of the organization; it's obvious that these results cannot emphasis on cooperative management as a solution to all management problems of an organization, since participation sysyem has its own limitations and issues. Thus, successful implementation of any participation, firstly would depend on the requirements of a company, the presence of favorable backgrounds, and the availability of prerequisites of participation, and secondly on the right way of implementing it. However, the growth and development of participation (cooperation) phenomenon here in Iran is still at the beginning of its long way, so, its growth and development path is not so smooth and is facing various obstacles. But the general trend in public (and even private) sector organizations confirms that the ruling situation in these organizations is traditional and non-entrepreneurial. Findings of the present study confirms that if implementation of cooperative management in different ways involves employee participation in decision making, goal setting, 
problem solving, and changes in the organization by applying participation (cooperation) methods through offering suggestions, attending the meetings, etc..., it would greatly promote organizational agility in transportation companies. In general, by concluding the above findings we can confirm a major hypothesis that"Cooperative management affects organizational agility through the mediating role of employee empowerment.

\section{CONCLUSIONS, RECOMMENDATIONS AND LIMITATIONS}

Today, organizations face a complex environment and a growing world. Therefore, organizations face with new challenges for continuing and deploying that overcoming these challenges requires more attention to the development and promotion of internal skills and capabilities of the organization (Ghafuri et al. 2014). This is done through employee empowerment and the principle of cooperative management for decision-making that is used by organizations to achieve better performance in the business world. Moreover, publictransportation system plays an important role in modern cities because it transfers a large group of passengers daily at low prices. At the same time, public transportation system is one of the safest modes of transport with the lowest mortality rate in recent years (Qiu \& Li 2018). Therefore, this research investigated the role of cooperative management system on organizational agility with the mediating role of employee empowerment in the public transportation sector. The results showed that there is a positive relationship between employee cooperative management and organizational agility. As such, the first hypothesis of the research was confirmed. These results are consistent with the findings of Davis and Newstrom (1989), Afjeh (2003) and others. According to the second hypothesis, there is a positive relationship between employee cooperative management and employee empowerment. The results of the research thus confirm the second hypothesis. The obtained results confirm the findings of Rahmati (2011), Toluei Far (2011), Tavakoli (2013), Iranzadeh \& Zanjani (2013), Jackson (1983) and Stump (2001). Based on the third hypothesis, employee empowerment has a positive effect on the organizational agility. The results of the research confirm this hypothesis too. This confirms the results of Azizi Asl (2015), Alzoubi (2011), Heidari (2013), Horabadi Farahani \& Salimi (2015), and Muduli (2017). The results of the research also confirm the fourth hypothesis stating that employee empowerment has a mediating role in the relationship between cooperative management and organizational agility. These results confirm the results of Rezaei Ali Babaloo et al. (2015) and GhalichKhani \& Hakkak (2016).

In line with the study, it can be suggested that leaders of organizations should help employees to get a complete picture along with basic trends, because the employees are the potential forces of the organization. They should be able to participate in systems thinking and cooperative management - a thinking that enhances their ability in predicting the effects of internal and external factors on the organization. Leaders of organizations must support their employees so that the employees could use a new way in which individuals understand themselves and the world around them, and consider themselves as being related to the world, not separate from it. In this regard, it is suggested that participatory atmosphere be further implemented within public transportation companies in order to increase order and discipline, and also to strengthen human relations between employees 
and company management. Management decisions within the organization can sooner or later change the fate of the company, so involvement of employees, particularly specialist forces in decision making process and organizational change seems logical and inevitable. Implementation of this, on the one hand, makes the organization more capable and efficient, and on the other hand it is one of the methods of maintaining expert and efficient forces in the company. It is suggested that managers of the organizations create an open and constructive atmosphere through involving the organization`s members and employees in decision making and conflict resolution, establishment of suggestion system, helping to meet the physical and mental needs, holding necessary training courses, meritocracy, creating a spirit of creativity and innovation, being up to date, and employing advisors and experts so that they can ensure th effectiveness of their organizations. Findings of the present thesis showed the significant positive effect of cooperative management and empowerment on organizational agility. Organizational agility requires organizational adaptability, continuous awareness of environmental opportunities and threats, internal capability of taking advantage of opportunities, and minimizing negative effects of the potential threats. Awareness of the needs of citizens, improvement of services provided for citizens, decision making through consensus, establishment of a favorable environment to advance change, and creating a sense of teamwork throughout the organization must be considered. In order to apply cooperative management more extensively, the level of individual preparedness of managers and employees must be increased, so that they could implement this system; these preparations include individuals` work maturity, willingness to participate, responsibility, and positive attitude towards subordinates and establishing a good relation with them. Promotion of workgroup culture based on cooperation would provide the necessary platform for empowering individuals. According to Dracker (1998), the present age is the age of knowledge-based works. Nowadays the main capital of institutions and organizations is their human resources as knowledge workers. Therefore managers of the organizations, affected by $21^{\text {st }}$ wave changes, have to rethink and recreate their methods, models, and thoughts regarging employed human resources.

Since the researcher produces research in the context of the scientific community, he is part of the scientific community and is not apart from it; therefore he is inspired by the previous research and can offer suggestions for future researchers. As the first step, it is suggested that a similar study be conducted with similar variables by applying adequate work force at the national level. Additionally, since the role of intervening and mediator variables has not been considered in this study, we suggest to future researchers that while investigating the impact of cooperative management on organizational agility, consider the role of these variables. It is suggested that future researchers study the relationship of empowerment and organizational agility with productivity. In addition, this was a case study of Tabriz \& Suburbs Bus Company; it is suggested that other researchers conduct a similar study in other organizations including service companies such as water and electricity companies, and service organizations like banks, etc., so that by comparing the results, more confidence and reliability is achived in applying the results.

Given the fact that this research has been carried out at the bus transportation organization in Tabriz, it is necessary to be cautious in generalizing the results to other organizations and companies. Despite serious effort to favorably implement research tools and make the employees of Tabriz \& Suburbs Bus Company aware of the goals and motivation 
of the research and responding to the questionnaire, we should not forget that they were not obliged to answer or give correct answers to the questions out of the scope of their duties. Also, index construction for each of the dimensions of the effective factors was a limitation, since some of the necessary indices might not fit into the mode. In spite of much effort, the researcher couldn't find any study dealing directly with the topic. Application of the questionnaire was a limitation of this study; also we could use another data collection tool such as interviews and observations, as well as documentary method or a combination of all four components above for hypothesis testing, however it was not possible because the research was time-consuming and the documentary information was not at hand.

\section{REFERENCES}

Abtahi, S. and Abbasi, S., 2007. Empowering employers. Institute of Management Researches and Educations. Tehran. (In Persian)

Afjeh, A. A., 2003. Philosophical foundations and theories of leadership and organizational behavior. SAMT Publication, 56. (In Persian)

Alitavakoli, S., 2013. The Study of Relationship between Collaborative Management and Empowerment of Teachers in Girls' High Schools of Kerman City in Years 92-93. Shahid Bahonar University of Kerman, Faculty of Literature and Human Sciences. (In Persian)

Alzoubi, A. E. H., Al-otoum, F. J., and Albatainh, A. K. F., 2011. Factors associated affecting organization agility on product development. International Journal of Research and Reviews in Applied Sciences, 9(3), 503-515.

Ardichvili, A., Cardozo, R. and Ray, S., 2003. A theory of entrepreneurial opportunity identification and development. Journal of Business venturing, 18, 105-123.

Azizi Asl, Shamsollah., Marzouqi, Rahmatullah., Jahani, Jafar., 2015. A Study of the Relationship between Psychological Empowerment of Human Resources and Organizational Agility. Research on Educational Leadership and Management, 1(4), 107-127. doi: 10.22054/jrlat.2015.4548. (In Persian)

Baird, K., Su, S., \& Munir, R. 2018. The relationship between the enabling use of controls, employee empowerment, and performance. Personnel Review, 47(1), 257-274.

Baird, K., \& Wang, H. 2010. Employee empowerment: Extent of adoption and influential factors. Personnel Review, 39(5), 574-599.

Baškarada, S., and Koronios, A., 2018. The 5S organizational agility framework: a dynamic capabilities perspective. International Journal of Organizational Analysis, 26(2), 331-342.

Burke, W., 1986. Leadership as empowering others. Executive power, 51-77.

Carlsson, L. and Berkes, F., 2005. Co-management: concepts and methodological implications. Journal of environmental management, 75, 65-76.

Cegarra-Navarro, J. G., Soto-Acosta, P., and Wensley, A. K., 2016. Structured knowledge processes and firm performance: The role of organizational agility. Journal of Business Research, 69(5), 1544-1549.

Davis, K. and Newstrom, J. W., 1989. Human behavior at work: Organizational behavior, McGraw-Hill. 
Dove, R., 2002. Response ability: the language, structure, and culture of the agile enterprise, John Wiley and Sons.

Erande, A. S. and Verma, A. K., 2008. Measuring agility of organizations-a comprehensive agility measurement tool (CAMT). International Journal of Applied Management and Technology, 6(3), 30-44.

Evans, L. and Guthrie, G., 2006. A Dynamic Theory of Cooperatives: The Link between Efficiency and Valuation. Journal of Institutional and Theoretical Economics, 162 (2), 364-383.

Fernandez, S., \& Moldogaziev, T. 2013. Employee empowerment, employee attitudes, and performance: Testing a causal model. Public Administration Review, 73(3), 490-506.

Gattiker, T. F., Chen, D. and Goodhue, D. L., 2005. Agility through standardization: A CRM/ERP application. Bendoly, E. and FR Jacobs (2005). Strategic ERP Extension and Use, Stanford University Press, Stanford, 87-96.

Ghafuri, P., Farhadi, A., and Mansouri, A., 2014. Relationship between intellectual capital and organizational agility with mediatory role of employee empowering in service sector (Case Study: Karafarin Insurance Company). International Journal of Economy, Management and Social Sciences, 3(12), 11-15. (In Persian)

GhalichKhani, R. D., and Hakkak, M., 2016. A Model for Measuring the Direct and Indirect Impact of Business Intelligence on Organizational Agility with Partial Mediatory role of Empowerment (Case Study: Tehran Construction Engineering Organization (TCEO) and ETKA Organization Industries. co). Procedia-Social and Behavioral Sciences, 230, 413-421. (In Persian)

Gilaninia, S., 2012. Determine the Effectiveness of Assertiveness Training on Student Achievement and Happiness. Journal of Basic and Applied, Scientific Research, 2(1), 141-144.

Goodwin, C., 2018. Co-operative action. New York, NY: Cambridge University Press. Maskell, B. (2001). The age of agile manufacturing. Supply Chain Management: An International Journal, 6 (1): 5-11.

Habibi, L, Falahati, M., 2004. Investigating and identifying the success factors of the proposal system (with emphasis on the public sector), Commercial Reviews, 23, 83-88. (In Persian)

Heydari, M., 2013. Investigating the multiple relationships between organizational learning, organizational agility features, organizational excellent empowerment based on the views of faculty members of Isfahan public universities. Isfahan University, Faculty of Psychology and Educational Sciences, PhD thesis. (In Persian)

Horabadi Farahani, A., and Salimi, F., 2015. The Study of the Relationship between Employees' Empowerment and Organizational Agility: A Case Study in Azarab Industrial Company. European Online Journal of Natural and Social Sciences: Proceedings, 4(1 (s)), 1067. (In Persian)

Idris, A., See, D., and Coughlan, P., 2018. Employee empowerment and job satisfaction in urban Malaysia: Connecting the dots with context and organizational change management. Journal of Organizational Change Management, 31(3), 697-711.

Iranzadeh, S., and Mahmoudi, M., 2010. Recognition and evaluation of organizational culture in the Denison's Model, Forouzesh Publications. (In Persian) 
Jackson, S. E., 1983. Participation in decision making as a strategy for reducing job-related strain. Journal of Applied Psychology, 68(1), 3-19.

Jahanian, R., 2009. Collaborative Management and a New Approach in the Administration of Organizations. Sarafraz Publications. (In Persian)

Janssen, L., 2010. Organizational agility in an institutional context. Supervisors: drs. MCP Nijssen and prof. dr. J. Paauwe.

Kirkman, B.L. and Shapiro, D.L., 2001. The impact of team members' cultural values on productivity, cooperation, and empowerment in self-managing work teams. Journal of cross-cultural psychology, 32(5), 597-617.

Lee, O. K., Sambamurthy, V., Lim, K. H., and Wei, K. K., 2015. How does IT ambidexterity impact organizational agility?. Information Systems Research, 26(2), 398-417.

Li, X., \& Holsapple, C. W. 2018. Entrepreneurial Work Design for Organization Agility. Journal of Management Policy and Practice, 19(3), 35-49.

Maskell, B., 2001. The age of agile manufacturing. Supply Chain Management: An International Journal, 6 (1): 5-11.

Matthiae, M., and Richter, J., 2018. Industry 4.0-Induced Change Factors and the Role of Organizational Agility. Muduli, A., 2017. Workforce agility: Examining the role of organizational practices and psychological empowerment. Global Business and Organizational Excellence, 36(5), 46-56.

Nasrollahi, Z, Push Duzbashi, H., 2017. Estimation of Air Pollution Caused by the Traffic of Public Urban Vehicles in Yazd. Journal of Environmental Science and Technology. (In Persian)

Nikbakht, M., Nawabakhsh, M., Jadidi, L and Fakhimi, A, 2014. Empowering human resources to improve organizational agility, $2^{\text {nd }}$ National Conference on Industrial Engineering and Systems, Islamic azad university, Najafabad branch, 25-26. (In Persian)

Oloko, M., \& Ogutu, M. 2017. Influence of power distance on employee empowerment and MNC performance: a study of multinational corporations in Kenya.

Overby, E., Bharadwaj, A. and Sambamurthy, V. 2006. Enterprise agility and the enabling role of information technology. European Journal of Information Systems, 15, 120-131.

Parkhurst, J. M., Price, G. J., Sharrock, P. J., and Moore, C. J. 2013. A visual patient feedback device using optical surface measurement for the cooperative management of setup and body dynamics during radiotherapy. Biomedical Signal Processing and Control, $8(6), 596-602$.

Qin, R. and Nembhard, D. A. 2010. Workforce agility for stochastically diffused conditions-A real options perspective. International Journal of Production Economics, 125, 324-334.

Qiu, G., and Li, L. 2018. Key factors to annual investment in public transportation sector: The case of China. Transportation Research Part A: Policy and Practice, 107, 1-19.

Ranjbar, Rahim., 1998. Evaluation of participatory management on the effectiveness of employees at Behran Oil Company, Master's Degree, Faculty of Administrative and Economic Sciences, University of Isfahan. (In Persian)

Rahmati, Z., 2011. The Relationship between Collaborative Management and Empowerment with Employees' Productivity of Rafsanjan's Pistachio Company in 2011" Marvdasht Islamic Azad University, Faculty of Science Educational and Psychology. (In Persian) 
Rezaei Ali Babaloo, H, Hazrati, M, Jamaati, Sh., 2015. Investigating the Relationship of Cooperative Management with Justice Perception and Empowerment of Employees of Supportive Institutions (A Case Study of Imam Khomeini Relief Committee in Ardabil Province). Fourth National Conference on Economics, Management and Iranian Islamic Culture, Ardebil, Iran. (In Persian)

Rezaei Ali Babaloo, H, Hazrati, M, Jamaati, Sh; 2015, Investigating the relationship between participatory management and the ability of support staff, Fourth National Conference on Economics, Management and Iranian Islamic Culture, Ardebil, Iran. (In Persian)

Seo, D. and La Paz, A. I. 2008. Exploring the dark side of IS in achieving organizational agility. Communications of the ACM, 51, 136-139.

Sharifi, H. and Zhang, Z., 2001. Agile manufacturing in practice-Application of a methodology. International Journal of Operations and Production Management, 21, 772-794.

Sofijanova, E. and Zabijakin-Chatleska, V., 2013. Employee involvement and organizational performance: evidence from the manufacturing sector in Republic of Macedonia. The International Scientific Conference "Business and Regional Development". Trakia University, Bulgaria.

Tallon, P. P., Queiroz, M., Coltman, T., and Sharma, R. 2018. Information technology and the search for organizational agility: A systematic review with future research possibilities. The Journal of Strategic Information Systems.

Teece, D., Peteraf, M., \& Leih, S. 2016. Dynamic capabilities and organizational agility: Risk, uncertainty, and strategy in the innovation economy. California Management Review, 58(4), 13-35.

Tolouei FAR, M. 2011. A Study of Relationship between Collaborative Management and Psychological Empowerment of the General Office's Employees of the Health Services in Tehran Province. Payame Noor University, Faculty of Humanities. (In Persian)

Van Oosterhout, M., Waarts, E. and Van Hillegersberg, J. 2006. Change factors requiring agility and implications for IT. European Journal of Information Systems, 15, 132-145.

Yaghoubi, N. M., Kord, B., and Azadikhah, O. 2011. Assessing organizational agility via fuzzy logic. International Business Research, 4(3), 135-144. (In Persian)

Zimmerman, M. A. 1990. Taking aim on empowerment research: On the distinction between individual and psychological conceptions. American Journal of community psychology, 18, 169-177. 
